\title{
Radar scattering from ice aggregates using the horizontally aligned oblate spheroid approximation
}

Article

Published Version

Hogan, R., Tian, L., Brown, P. R.A., Westbrook, C., Heymsfield, A. J. and Eastment, J. D. (2012) Radar scattering from ice aggregates using the horizontally aligned oblate spheroid approximation. Journal of Applied Meteorology and Climatology, 51 (3). pp. 655-671. ISSN 1558-8432 doi: https://doi.org/10.1175/JAMC-D-11-074.1 Available at https://centaur.reading.ac.uk/28398/

It is advisable to refer to the publisher's version if you intend to cite from the work. See Guidance on citing.

To link to this article DOI: http://dx.doi.org/10.1175/JAMC-D-11-074.1

Publisher: American Meteorological Society

All outputs in CentAUR are protected by Intellectual Property Rights law, including copyright law. Copyright and IPR is retained by the creators or other copyright holders. Terms and conditions for use of this material are defined in the End User Agreement. 


\section{CentAUR}

Central Archive at the University of Reading

Reading's research outputs online 


\title{
Radar Scattering from Ice Aggregates Using the Horizontally Aligned Oblate Spheroid Approximation
}

\author{
Robin J. Hogan, ${ }^{*}$ Lin Tian, ${ }^{+}$Philip R. A. Brown, ${ }^{\#}$ Christopher D. Westbrook,* \\ ANDREW J. HEYMSFIELD, ${ }^{@}$ AND JON D. EASTMENT ${ }^{\&}$ \\ * Department of Meteorology, University of Reading, Reading, United Kingdom \\ ${ }^{+}$Goddard Earth Science and Technology Center, University of Maryland, Baltimore County, Baltimore, Maryland \\ \# Met Office, Exeter, United Kingdom \\ @ National Center for Atmospheric Research,** Boulder, Colorado \\ ${ }^{\&}$ Rutherford Appleton Laboratory, Didcot, United Kingdom
}

(Manuscript received 6 April 2011, in final form 26 October 2011)

\begin{abstract}
The assumed relationship between ice particle mass and size is profoundly important in radar retrievals of ice clouds, but, for millimeter-wave radars, shape and preferred orientation are important as well. In this paper the authors first examine the consequences of the fact that the widely used "Brown and Francis" masssize relationship has often been applied to maximum particle dimension observed by aircraft $D_{\max }$ rather than to the mean of the particle dimensions in two orthogonal directions $D_{\text {mean }}$, which was originally used by Brown and Francis. Analysis of particle images reveals that $D_{\max } \simeq 1.25 D_{\text {mean }}$, and therefore, for clouds for which this mass-size relationship holds, the consequences are overestimates of ice water content by around $53 \%$ and of Rayleigh-scattering radar reflectivity factor by $3.7 \mathrm{~dB}$. Simultaneous radar and aircraft measurements demonstrate that much better agreement in reflectivity factor is provided by using this mass-size relationship with $D_{\text {mean }}$. The authors then examine the importance of particle shape and fall orientation for millimeter-wave radars. Simultaneous radar measurements and aircraft calculations of differential reflectivity and dual-wavelength ratio are presented to demonstrate that ice particles may usually be treated as horizontally aligned oblate spheroids with an axial ratio of 0.6 , consistent with them being aggregates. An accurate formula is presented for the backscatter cross section apparent to a vertically pointing millimeter-wave radar on the basis of a modified version of Rayleigh-Gans theory. It is then shown that the consequence of treating ice particles as Mie-scattering spheres is to substantially underestimate millimeter-wave reflectivity factor when millimeter-sized particles are present, which can lead to retrieved ice water content being overestimated by a factor of 4 .
\end{abstract}

\section{Introduction}

Millimeter-wave radars are an excellent tool for probing the properties of ice clouds and hence for evaluating their representation in weather and climate models (e.g., Stokes and Schwartz 1994; Illingworth et al. 2007). The wide range of possible ice particle shapes therefore poses a problem, since their scattering behavior at the radar

** The National Center for Atmospheric Research is sponsored by the National Science Foundation.

Corresponding author address: Robin J. Hogan, Dept. of Meteorology, Earley Gate, P.O. Box 243, Reading, RG6 6BB, United Kingdom.

E-mail: r.j.hogan@reading.ac.uk wavelength must be modeled if cloud properties are to be retrieved accurately from such measurements. In general, scattered signals are insensitive to structure within the particle that is at a scale much smaller than the wavelength. Most ground-based cloud radars operate at a wavelength of $8.6 \mathrm{~mm}$ ( $35 \mathrm{GHz})$, for which ice particles tend to be small enough to scatter in the Rayleigh regime. From space, however, the requirement for high sensitivity, a narrow beamwidth, and a small antenna size meant that a wavelength of $3.2 \mathrm{~mm}(94 \mathrm{GHz})$ was the only viable choice for CloudSat (Stephens et al. 2002). At this wavelength the particles are often large enough that the Rayleigh approximation no longer applies and moresophisticated scattering calculations are required.

By far the most common assumption in developing 94-GHz radar retrieval methods is to treat ice particles 
as spheres consisting of a homogeneous mixture of ice and air and to apply Mie theory (e.g., Brown et al. 1995; Hogan and Illingworth 1999; Donovan et al. 2001; Hogan et al. 2006; Delanoë and Hogan 2008; Austin et al. 2009). The appropriate mass-size relationship is then sometimes reformulated in terms of the effective density of these equivalent spheres (Heymsfield et al. 2004). For radar scattering, however, the question arises as to which is the appropriate diameter to use: is it the diameter of the smallest sphere that completely encloses the particle, the diameter of the sphere with the same geometric cross section as the particle (e.g., as observed by an aircraft probe), or something else? While the first assumption is the most common, Donovan et al. (2004) found that the equivalent-area sphere gave a better approximation to $94-\mathrm{GHz}$ backscatter calculated using the discrete dipole approximation (DDA) for selected pristine crystal habits, although orientation was also found to be important. O'Brien and Goedecke (1988) and Schneider and Stephens (1995) performed DDA calculations on hexagonal columns, plates, and dendritic snowflakes and found that approximating the ice particle by its equivalent oblate or prolate spheroid led to an error in general of less than $15 \%(0.6 \mathrm{~dB})$, provided maximum dimension, axial ratio, total ice mass, and orientation were maintained. Hogan et al. (2000) argued that because deviations from Rayleigh scattering arise as a result of destructive interference from radiation scattered from the near and far sides of the particle, it is actually the dimension of the particle in the direction that the radar is looking that is important (usually the vertical dimension for cloud radars).

Given these findings, we need to know the dominant particle shape and orientation in ice clouds. In terms of shape, large datasets of aircraft images have revealed that most of the time the size distribution is dominated by irregular particles (Korolev et al. 1999, 2000)-in particular, well away from the cores of convective clouds or mixed-phase regions. Irregular particles larger than around $70 \mu \mathrm{m}$ typically have an axial ratio of $0.6-0.65$ (Korolev and Isaac 2003). Theoretical and modeling studies of the aggregation process by Westbrook et al. (2004) not only support this range of axial ratio but also have shown that the observed tendency for particle mass to be approximately proportional to the square of particle size in ice clouds spanning a wide range of temperatures is characteristic of aggregation. Furthermore, in individual clouds the rate of increase of radar reflectivity factor with time as particles fall from cloud top to cloud base is consistent with the process of aggregation (Westbrook et al. 2007).

Aircraft observations unfortunately cannot be used to infer the natural fall orientation of ice particles, since turbulence around the probe inlets and the distorted flow around the aircraft fuselage tend to reorient them (e.g., King 1985, 1986). Particles that fall with a Reynolds number between 1 and around 100 are known to fall with their largest dimension in the horizontal plane (Pruppacher and Klett 1997), however, and almost all ice particles in natural clouds have Reynolds numbers in this range (except for the largest centimeter-sized aggregates near the melting layer). This has been confirmed by lidar from the difference between the backscatter when pointing directly at zenith and when pointing a few degrees from zenith (Sassen 1977; Platt et al. 1978; Thomas et al. 1990; Westbrook et al. 2010), at least in the clouds that the lidar can penetrate. It is also confirmed by differential reflectivity observations by horizontally pointing radar that show that stratiform ice clouds have a larger reflectivity factor when measured at horizontal polarization than at vertical polarization (Hall et al. 1984; Bader et al. 1987; Hogan et al. 2002, 2003). Matrosov et al. (2005b) went further, using the linear depolarization ratio observed by radar at a range of elevation angles to demonstrate that ice dendrites fall with a predominantly horizontal orientation but "flutter" with a standard deviation of only approximately $9^{\circ}$. A similar picture was found for particles with less-extreme aspect ratio (Matrosov et al. 2001). This deviation from horizontal orientation is small enough to be neglected in scattering calculations. These findings suggest that a better model for radar scattering than spheres would be horizontally aligned oblate or prolate spheroids, but any approximation made in calculating their scattering properties needs to be tested by comparing real radar observations with calculations performed on ice particle size distributions observed simultaneously by aircraft.

In section 2 of this paper, the importance of using consistent definitions of particle size for interpreting aircraft-measured size distributions is demonstrated in the context of the fact that the widely used Brown and Francis (1995) mass-size relationship has often been applied to a different measure of particle size than was used by Brown and Francis. In section 3, we use particle imagery from aircraft to hypothesize that, for radar scattering, ice particles may be treated as horizontally aligned oblate spheroids with an axial ratio of $0.6-a$ model originally proposed by Matrosov et al. (2005a). We test this model in sections 4 and 5 using coincident radar and aircraft observations, first in its ability to predict differential reflectivity observations, and then in its ability to predict the difference in reflectivity factor measured by $10-$ and $94-\mathrm{GHz}$ radars. Then in section 6 , the implications of this scattering model for retrievals of ice water content (IWC) are explored by recalculating the empirical relationships of Hogan et al. 


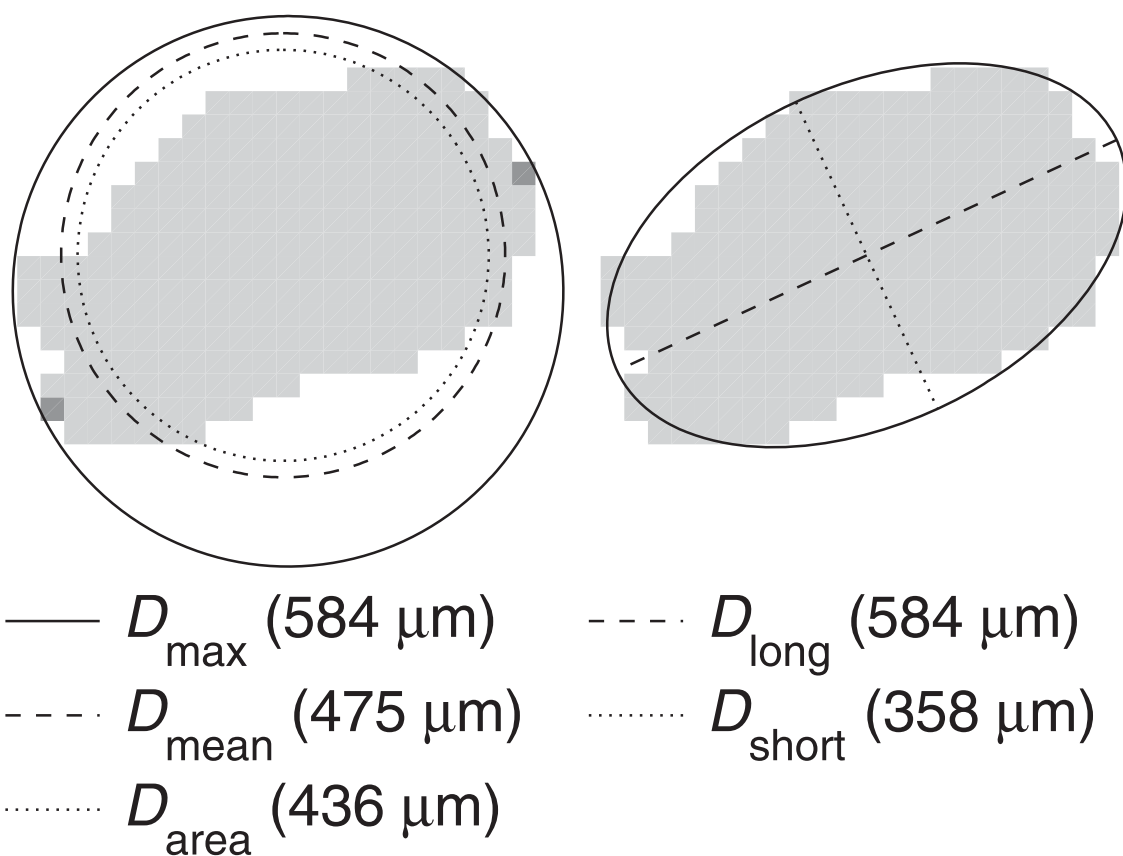

FIG. 1. Sample ice particle image from the 2D-C probe, which has $25-\mu \mathrm{m}$ pixels. Superimposed on the left version are circles with diameters equal to the maximum dimension $D_{\max }$, the mean dimension $D_{\text {mean }}$, and the equivalent-area diameter $D_{\text {area }}$. The two most-separated pixels in the image are shown in dark gray and were used to calculate $D_{\max }$; this circle has its center half way between these two pixels. The other two circles are centered on the center-ofmass of the image. Superimposed on the right version of the same image is an ellipse with its major and minor axes having dimensions $D_{\text {long }}$ and $D_{\text {short }}$ (defined in the appendix). Each measure of size is listed to the nearest micrometer below the image.

(2006) for estimating IWC from radar reflectivity factor and temperature.

\section{Measures of ice particle size}

Most studies of aircraft-measured particle size distributions use the "maximum dimension" $D_{\max }$ to characterize the size of each particle. For an imaging probe such as the $2 \mathrm{D}$ cloud probe $(2 \mathrm{D}-\mathrm{C}$; size range $25-$ $800 \mu \mathrm{m})$ or $2 \mathrm{D}$ precipitation probe (2D-P; size range 0.2-6.4 mm) (Knollenberg 1970), the simplest way to define this is as the maximum distance between the centers of two pixels in a $2 \mathrm{D}$ particle image, plus the width of one pixel. (Note that another definition is the diameter of the smallest circle that completely circumscribes the image, but usually this is the same.) The left image in Fig. 1 shows a circle of diameter $D_{\max }$ surrounding an ice particle imaged by the $2 \mathrm{D}-\mathrm{C}$ probe; all pixels in the image lie within the circle.

For the 2D probes on the U.K. meteorological research aircraft (first the C-130 Hercules and now the BAe-146), the standard processing involves analysis of the particle images to calculate their dimensions in the directions parallel and perpendicular to the photodiode array: $D_{x}$ and $D_{y}$. Because the probes are configured to look down on the particles from above, these are the dimensions of the particle perpendicular and parallel to the direction in which the aircraft is traveling. Ice particle size spectra are then generated in terms of the "mean" dimension, defined as

$$
D_{\text {mean }}=\left(D_{x}+D_{y}\right) / 2 .
$$

The resulting spectra have been used to estimate relationships between particle mass and size. For example, the following relationship between mass $m$ and $D_{\text {mean }}$ was found by Brown and Francis (1995) to give the best agreement between the IWC inferred from 2D probes and that from an independent evaporative technique when applied to a dataset of midlatitude ice cloud observations mostly in the temperature range from $-20^{\circ}$ to $-30^{\circ} \mathrm{C}$ :

$$
\begin{aligned}
& m=480 D_{\text {mean }}^{3} ; \quad D_{\text {mean }}<9.7 \times 10^{-5} \mathrm{~m}, \\
& m=0.0185 D_{\text {mean }}^{1.9} ; \quad D_{\text {mean }} \geq 9.7 \times 10^{-5} \mathrm{~m},
\end{aligned}
$$

where $m$ is in kilograms and $D_{\text {mean }}$ is in meters. The first part of this relationship ensures that at small sizes the 
density does not exceed the value of a solid ice sphere with diameter $D_{\text {mean }}$. It was found by Hogan et al. (2006) to give a very good match between radar reflectivity factor measured by $9.75-\mathrm{cm}$-wavelength radar and that calculated by aircraft when applied to $D_{\text {mean }}$, in singlephase midlatitude ice clouds. At this wavelength, ice particles are small enough that Rayleigh scattering can be assumed, for which reflectivity factor is proportional to the square of the particle mass but for a given mass is approximately independent of particle size. Therefore, the fact that Hogan et al. (2006) found that the reflectivity-factor bias from individual aircraft runs was no more than $1 \mathrm{~dB}$ suggests that (2) is accurate to $12 \%$, at least for the larger particles in the distribution to which the radar is sensitive.

Because $D_{x}$ and $D_{y}$ must be equal to or smaller than $D_{\text {max }}, D_{\text {mean }}$ must be systematically smaller than $D_{\max }$. An issue of concern is that (2) has sometimes been applied to particle distributions with the size characterized by $D_{\max }$, with the implicit assumption that $D_{\max } \simeq$ $D_{\text {mean }}$. As just one example, three of the authors of the present paper have applied it to aircraft data from the Central Equatorial Pacific Experiment, which was binned by $D_{\max }$ (Brown et al. 1995; Hogan and Illingworth 1999). Because in reality $D_{\max }>D_{\text {mean }}$, this implies that both IWC and Rayleigh-scattering reflectivity factor would be overestimated. It was pointed out by Heymsfield et al. (2010) that (2) was originally taken from the expression for "aggregates of unrimed bullets, columns and side-planes" of Locatelli and Hobbs (1974), who used the equivalent-area diameter $D_{\text {area }}$ rather than $D_{\text {mean }}$. The left image of Fig. 1 illustrates that these two measures are not the same, although in this case they are much more similar to each other than they are to $D_{\text {max }}$. In any case, Locatelli and Hobbs (1974) derived this particular expression as a fit through only 19 particles measured at the ground, and therefore the heritage of the expression does not in itself provide strong support for the use of $D_{\text {area }}$ rather than $D_{\text {mean }}$ in the widespread application of (2).

So how different are $D_{\text {mean }}$ and $D_{\max }$ ? The ice particle image that is shown in Fig. 1 measures 22 pixels in the horizontal and 16 pixels in the vertical directions so that, given that the pixel size is $25 \mu \mathrm{m}, D_{\text {mean }}$ is $475 \mu \mathrm{m}$. For this particular particle, $D_{\max }$ is $23 \%$ larger. To investigate the relationship between $D_{\text {mean }}$ and $D_{\max }$ more generally, we have analyzed particle images from the four runs of the C-130 aircraft in single-phase ice clouds shown by Hogan et al. (2006) plus two other images, spanning the temperature range from $-32^{\circ}$ to $-9^{\circ} \mathrm{C}$. The sample rate of the $2 \mathrm{D}$ probes on the $\mathrm{C}-130$ aircraft was slaved to the true airspeed to ensure that the pixel spacing in the across- and along-track directions was equal, but for true airspeed greater than $125 \mathrm{~m} \mathrm{~s}^{-1}$ the sample rate was fixed

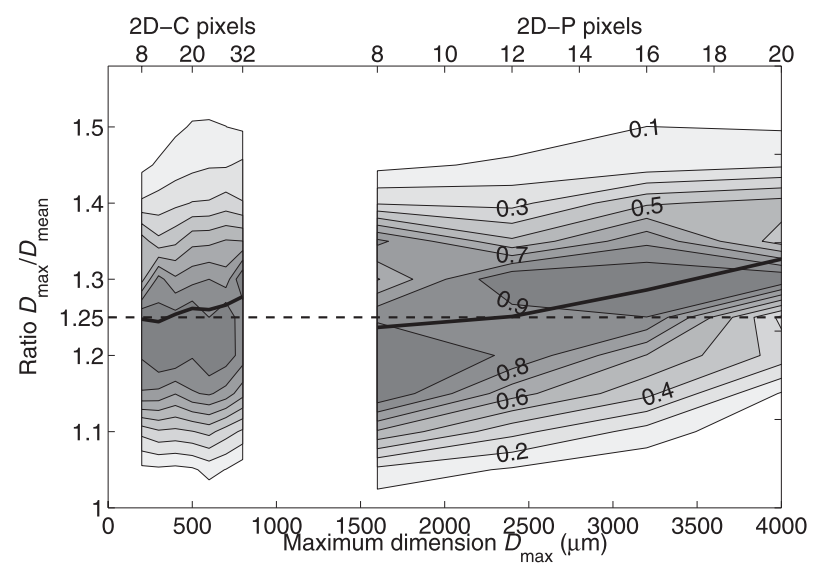

FIG. 2. The ratio $D_{\max } / D_{\text {mean }}$ for individual ice particles vs $D_{\max }$ for images measured by the probes on the U.K. meteorological research aircraft from six straight and level runs on four different days, corresponding to the runs shown in Figs. 1, 2, 4, and 5 of Hogan et al. (2006) plus an additional run on 20 Oct 1998, and a run on 8 Oct 1997 (shown in Fig. 6a, described below). The shaded contours indicate the probability density normalized by the peak value at that particular value of $D_{\text {max }}$. The distribution is not shown for images with a $D_{\max }$ that corresponds to fewer than eight pixels, because in that case the image is judged not to be sufficiently resolved for this ratio to be inferred reliably. Because the widths of the photodiode arrays are only 32 pixels, particles with $D_{\text {max }}$ larger than this are not shown to avoid preferential sampling of particles with extreme axial ratios. Too few particles of $D_{\max }>4 \mathrm{~mm}$ are present in this sample to yield reliable statistics for these sizes. The thick solid line indicates $\left(\overline{D_{\text {max }}^{2}} / \overline{D_{\text {mean }}^{2}}\right)^{1 / 2}$.

at the value for $125 \mathrm{~m} \mathrm{~s}^{-1}$. Therefore, for the two runs above $6 \mathrm{~km}$ when the true airspeed was greater than this value, it has been necessary to account for this asymmetry in calculating $D_{\max }$ and $D_{\text {mean }}$.

Figure 2 shows the distribution of the ratio $D_{\max } /$ $D_{\text {mean }}$ for over $850002 \mathrm{D}$-C images and over 55000 2D-P images. Only size ranges for which this ratio can be inferred unambiguously have been shown. We wish to calculate a mean ratio between these two measures of size such that mass-size relationships such as the one shown by (2) may be rewritten in terms of $D_{\max }$. The usual situation in such relationships is that the mass of complex polycrystals and aggregates larger than $100 \mu \mathrm{m}$ is proportional to particle size to the power of approximately 2 (e.g., Mitchell 1996). Therefore, the appropriate average ratio is given by $\left(\overline{D_{\max }^{2}} / \overline{D_{\text {mean }}^{2}}\right)^{1 / 2}$. This is shown versus $D_{\max }$ by the thick solid line in Fig. 2. Note that this line is only moved by $0.05 \%$ if a power of 1.9 is used as in (2), that is, if we calculate $\left(\overline{D_{\text {max }}^{1.9}} / \overline{D_{\text {mean }}^{1.9}}\right)^{1 / 1.9}$. This insensitivity is fortunate given the range of exponents that have been fitted to aircraft data (e.g., Heymsfield et al. 2007). There is a weak increasing trend with $D_{\max }$, but for particles smaller than around $3 \mathrm{~mm}$ the ratio is $1.25 \pm 0.05$. Therefore, throughout this paper we make the approximation that 


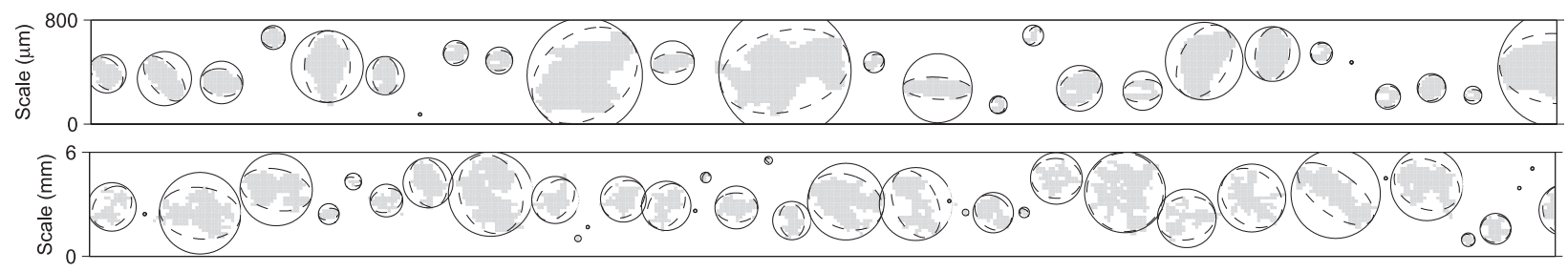

FIG. 3. Sample images from (top) the 2D-C probe in a midlatitude ice cloud on 21 Nov 2000 and (bottom) the 2D-P probe in a midlatitude ice cloud on 20 Oct 1998. Over each particle image, a solid circle with a diameter of $D_{\max }$ and a dashed ellipse with major dimension $D_{\text {long }}$ and minor dimension $D_{\text {short }}$ (defined in the appendix) have been drawn. Note that the orientation of the particles is randomized when they enter the probe.

$$
D_{\text {max }} \simeq 1.25 D_{\text {mean }} .
$$

In section 3 it will be shown that this approximation is consistent with the mean ice particle axial ratio found in this aircraft dataset and reported by other authors, which in turn is consistent with the radar observations that are described later in this paper. We do not exclude the possibility that future work (e.g., with higher-resolution probes) will find a slightly better fit-for example, to represent a slight increase of this coefficient at larger sizes.

If we wish to use the Brown and Francis (1995) relationship to aircraft ice particle size distributions that are reported in terms of $D_{\max }$, then it is necessary to use (3) to convert to $D_{\text {mean }}$ before applying (2). Otherwise, the mass of each particle, and hence the IWC, will be overestimated by a factor of $(1.25 \pm 0.05)^{1.9}=1.53 \pm$ 0.12 . This overestimate is consistent with that shown in Fig. 1a of Heymsfield et al. (2010).

The consequences for radar reflectivity factor (which is the main subject of this paper) are even more dramatic, because the fact that in the Rayleigh regime it is proportional to mass squared implies that it would be overestimated by a factor of $(1.25 \pm 0.05)^{3.8}=2.33 \pm 0.35$, or $3.67 \pm 0.65 \mathrm{~dB}$. An error of this magnitude is certainly not consistent with the comparison of reflectivity factor measured by radar and calculated by aircraft using (2) applied to $D_{\text {mean }}$ (Hogan et al. 2006). For convenience, we present the Brown and Francis (1995) relationship in terms of $D_{\max }$ by performing this scaling to mass:

$$
\begin{aligned}
& m=480 D_{\text {max }}^{3} ; \quad D_{\text {max }}<6.6 \times 10^{-5} \mathrm{~m}, \\
& m=0.0121 D_{\text {max }}^{1.9} ; \quad D_{\text {max }} \geq 6.6 \times 10^{-5} \mathrm{~m},
\end{aligned}
$$

and we recommend that this expression be used when radar reflectivity factor is required and particle size distributions are expressed in terms of $D_{\max }$. Note that in the absence of accurate measurements of $D_{\text {mean }}$ and $D_{\text {max }}$ for particles smaller than approximately $100 \mu \mathrm{m}$, this expression assumes the particles to be quasi spherical $\left(D_{\max }=\right.$ $D_{\text {mean }}$ ) for $D_{\text {max }}<66 \mu \mathrm{m}$, with the ratio $D_{\text {max }} / D_{\text {mean }}$ then increasing linearly with $D_{\max }$ up to $D_{\max }=97 \mu \mathrm{m}$, whereafter (3) applies.

\section{The axial ratio of ice particles}

We now use the same data as in the previous section to estimate the axial ratio of ice particles. If free-falling ice particles have a preferentially horizontal orientation, then their axial ratio is important for calculating their scattering properties correctly-in particular, for vertically pointing millimeter-wave radar. The appendix describes a method for finding the major axis of a particle image and then estimating the length of its longest and shortest dimensions, $D_{\text {long }}$ and $D_{\text {short }}$, in perpendicular directions; we then define axial ratio as $\alpha=$ $D_{\text {short }} / D_{\text {long. }}$. The right-hand image in Fig. 1 indicates that the corresponding ellipse can provide a much better approximation to the shape of the particle than can a circle, and in this case $\alpha=0.61$. Figure 3 shows circles and ellipses fitted to ice aggregates observed by both the 2D-C and 2D-P probes, and again the ellipses provide visibly better fits to the images.

The same data as used in the previous section have been used to characterize the relationship between $D_{\text {long, }}$, $D_{\text {short }}$, and other measures of particle size. It has been found that $D_{\text {max }}$ is larger than $D_{\text {long }}$ but by only $1.5 \%-2 \%$, on average. Therefore, for the purposes of this paper, we shall assume them to be equal. Figure 4 depicts the distribution of $\alpha$ for the same data as used in Fig. 2. The thick solid line in Fig. 4 shows the logarithmic mean axial ratio, that is, $\exp (\overline{\ln \alpha})$ versus $D_{\text {max }}$ (this is used in preference to the linear mean, since the value of the linear mean of $\alpha$ is different from the equally valid reciprocal of the linear mean of $1 / \alpha$ ). It can be seen that there is a tendency for larger particles to exhibit more-extreme axial ratios, although the variation in the mean is less than the spread in axial ratios of individual particles. Analysis of a larger sample of aircraft data in frontal ice clouds between $0^{\circ}$ and $-40^{\circ} \mathrm{C}$ by Korolev and Isaac (2003) corroborates the finding that mean axial ratio typically lies between 0.6 and 0.65 , which are shown by the dashed lines in Fig. 4. 


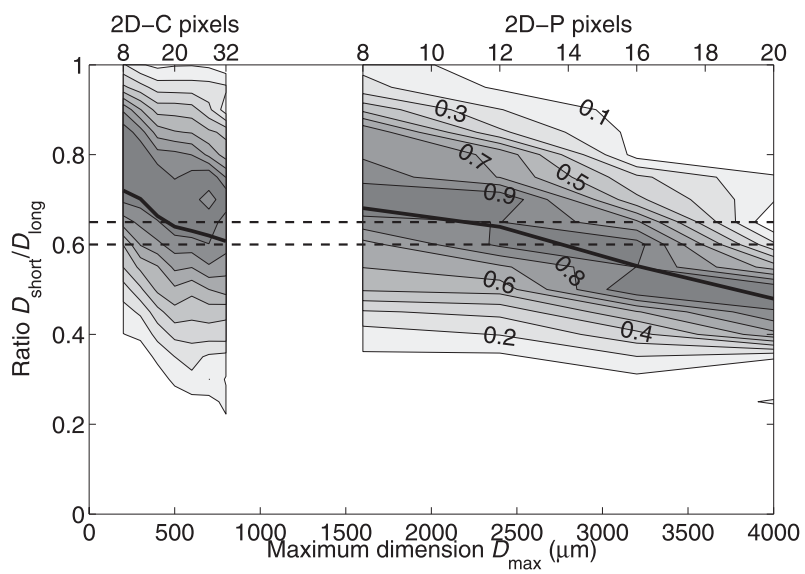

FIG. 4. As in Fig. 2 but for axial ratio $\alpha=D_{\text {short }} / D_{\text {long. }}$. The thick solid line indicates the logarithmic mean, and the dashed lines correspond to ratios of 0.6 and 0.65 .

This axial ratio is consistent with the relationship between $D_{\max }$ and $D_{\text {mean }}$ given by (3). Consider a particle whose shadow consists of an ellipse with $D_{\max }=1$ (arbitrary units) and an axial ratio of 0.6 . If this ellipse is rotated through $360^{\circ}$ (representing random orientation within the probe) then it can be shown numerically that the value of $D_{\text {mean }}$ given by (1) will oscillate between 0.8 and 0.825 , with a mean of 0.8125 . Thus $D_{\max } \simeq 1.23 D_{\text {mean }}$, which is very close to (3).

The observational studies discussed in the introduction suggest that ice particles naturally fall with their longest dimension in the horizontal plane, which is not detectable by aircraft given that the probe observes the particles from above and that they have been reoriented by turbulence in the vicinity of the probes and by the flow around the aircraft fuselage. We are really interested in the true axial ratio of freely falling particles, but it is likely in both this study and the study of Korolev and Isaac (2003) that particles will tend to look more circular, on average, since they will rarely be viewed "edge on" (i.e., rarely will the shortest dimension be exactly perpendicular to the viewing direction), and perhaps the true mean axial ratio is less than 0.6. Modeling of the process of aggregation by Westbrook et al. (2004) also finds axial ratios in the range $0.6-0.65$, however, and therefore we are motivated to choose the value at the lower end of this range.

Given this evidence, we make the hypothesis that for radar scattering applications it is reasonable to approximate ice particles in single-phase clouds as horizontally aligned oblate spheroids with a major-axis dimension of $D_{\max }$ and an axial ratio of 0.6 , consisting of a homogeneous mixture of ice and air with a mass given by (4). The test of our hypothesis is in its ability to fit radar observations, and in the next two sections it is evaluated using coincident radar and aircraft data.

\section{Application to polarimetric centimeter- wavelength radar observations}

Hogan et al. (2006) compared radar reflectivity factor calculated from aircraft in situ sampling with the values measured directly by the scanning $3-\mathrm{GHz}$ (wavelength $\lambda=9.75 \mathrm{~cm}$ ) radar at Chilbolton, southern England, in single-phase ice clouds. They found that the Brown and Francis (1995) mass-size relationship, applied to aircraft size distributions binned by $D_{\text {mean }}$, performed very well. In this section we extend their analysis to compare also the differential reflectivity, defined as

$$
Z_{\mathrm{dr}}=10 \log _{10}\left(Z_{h} / Z_{v}\right)
$$

the Chilbolton radar transmits alternate horizontally and vertically polarized pulses, and $Z_{h}$ and $Z_{v}$ are the corresponding radar reflectivity factors measured at the two polarizations. For spheres, $Z_{h}=Z_{v}$ and so $Z_{\mathrm{dr}}=0 \mathrm{~dB}$, but for particles with a larger extension in the horizontal than the vertical (e.g., horizontally aligned oblate spheroids), the horizontally polarized beam from the radar induces a larger dipole moment than the vertically polarized beam, resulting in $Z_{h}>Z_{v}$, and $Z_{\mathrm{dr}}$ is positive.

Reflectivity factor (or strictly "effective" reflectivity factor) may be defined as the summation of the backscatter cross section $\sigma$ of the individual particles in a unit volume of air $V$ :

$$
Z_{h}=\frac{\lambda^{4}}{\pi^{5}\left|K_{r}\right|^{2}} \sum_{V} \sigma_{h},
$$

and similarly for $Z_{v}$, where $\left|K_{r}\right|^{2}$ is a reference dielectric factor that defines the calibration convention. Hogan et al. (2006) used a value of 0.93 , which ensures that a millimeter-wavelength radar will measure the same reflectivity factor as a centimeter-wavelength radar in Rayleigh scattering ice cloud, thereby allowing the combination to be used to estimate particle size. The CloudSat radar (Stephens et al. 2002) uses a value of 0.75 .

\section{a. Dependence of differential reflectivity on density and axial ratio}

At a wavelength of $9.75 \mathrm{~cm}$, we may assume the ice particles to be much smaller than the wavelength and use the Gans (1912) extension to Rayleigh theory (van de Hulst 1957), which provides a simple analytical description of the polarized backscattering from homogeneous oblate spheroids. Seliga and Bringi (1976) used this to calculate the $Z_{\mathrm{dr}}$ from oblate raindrops, whereas Hogan et al. (2002) used it to calculate the $Z_{\mathrm{dr}}$ of oblate and prolate ellipsoidal approximations to pristine ice plates and columns. In this approach, the 
backscatter cross section in (6), and in the equivalent equation for $Z_{v}$, is given by

$$
\begin{aligned}
& \sigma_{h}=\frac{\pi^{5} D_{\mathrm{vol}}^{6}}{\lambda^{4}}\left|\frac{(\varepsilon-1) / 3}{1+(\varepsilon-1) L^{\prime}}\right|^{2} \text { and } \\
& \sigma_{v}=\frac{\pi^{5} D_{\mathrm{vol}}^{6}}{\lambda^{4}}\left|\frac{(\varepsilon-1) / 3}{1+(\varepsilon-1) L}\right|^{2},
\end{aligned}
$$

where $D_{\mathrm{vol}}$ is the volumetric equivalent diameter, which for an oblate spheroid is given by

$$
D_{\mathrm{vol}}=D_{\mathrm{short}}^{1 / 3} D_{\max }^{2 / 3}=\alpha^{1 / 3} D_{\max },
$$

and $\varepsilon$ is the dielectric constant of the ice-air mixture. The mass and volume of the spheroid are used to work out the density of this mixture, and then the MaxwellGarnet (1904) mixing rule is used to calculate $\varepsilon$. The terms $L$ and $L^{\prime}$ are geometric factors given by

$$
L=\frac{1-L^{\prime}}{2}=\frac{1}{e^{2}}\left(1-\frac{\alpha \sin ^{-1} e}{e}\right),
$$

\section{(Eq. 10 is wrong: should be $L=1-2 L^{\prime}=\ldots$ )}

where the eccentricity is given by $e=\left(1-\alpha^{2}\right)^{1 / 2}$. For oblate spheroids with an axial ratio of $\alpha=0.6, L=$ 0.478 and $L^{\prime}=0.262$. For spheres, $L=L^{\prime}=1 / 3$, and the terms in the vertical bars in (7) reduce to the ClausiusMossotti factor

$$
K=(\varepsilon-1) /(\varepsilon+2) .
$$

Figure 5 depicts the differential reflectivity of individual particles as a function of axial ratio $\alpha$ and the fraction of the volume containing ice, calculated using the Gans (1912) theory. It can be seen that $Z_{\mathrm{dr}}$ increases approximately linearly as a function of each of these factors. This relationship is valid for particles much smaller than the radar wavelength, in which limit $Z_{\mathrm{dr}}$ is independent of particle size (keeping axial ratio fixed).

\section{b. Case studies}

We now use the Gans (1912) method to estimate $Z_{\mathrm{dr}}$ from distributions of particles sampled in situ by the U.K. meteorological aircraft and compare it with values measured simultaneously by the Chilbolton radar. Ice particle images from the $2 \mathrm{D}-\mathrm{C}$ and $2 \mathrm{D}-\mathrm{P}$ probes have been characterized by their mean dimension $D_{\text {mean }}$ and axial ratio $\alpha$ using the method described in sections 2 and 3. Mass has been calculated using (2). It is assumed that the apparent random orientation of the particles in Fig. 3 is purely due to turbulence as the particles are drawn into the probe, and under natural conditions the particles are oriented with their longest dimension in the

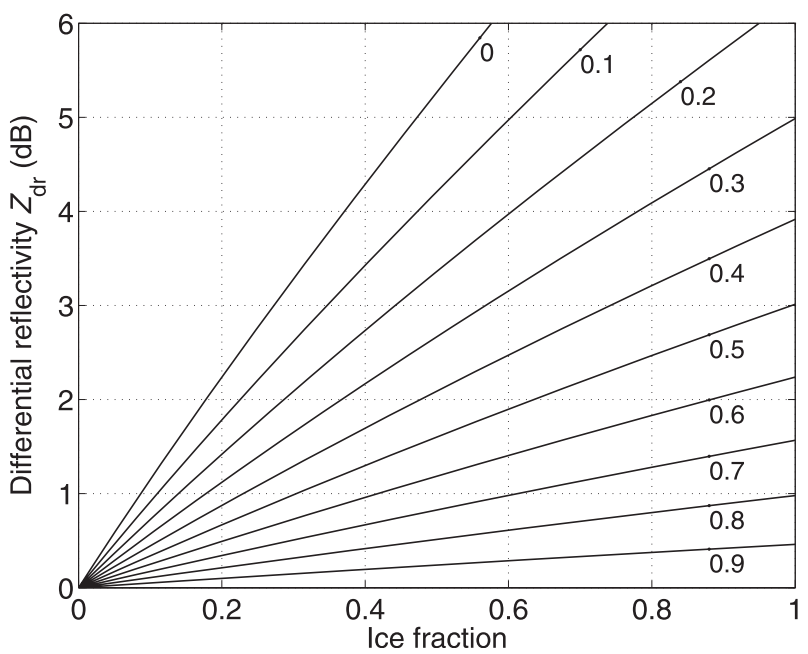

FIG. 5. Differential reflectivity vs ice fraction for individual horizontally aligned oblate spheroids composed of a homogeneous mixture of ice and air, where "ice fraction" is simply the actual particle mass divided by the mass of an oblate spheroid of the same size but composed of solid ice. Each line corresponds to a different axial ratio $\alpha$ as indicated. The calculations were performed using the Gans (1912) theory described in the text and are only valid for particles that are much smaller than the radar wavelength.

horizontal. With the assumption that the particles scatter as oblate spheroids, both $Z_{h}$ and $Z_{\mathrm{dr}}$ may be calculated to compare with the radar.

Figure 6 depicts three coincident scans of the Chilbolton radar and in situ sampling from the U.K. aircraft, in each case with a cloud top colder than $-40^{\circ} \mathrm{C}$. The radar reflectivity factor was calibrated to $0.5 \mathrm{~dB}$ using the redundancy of the polarimetric variables in heavy rain (Goddard et al. 1994; Gourley et al. 2009). Figures $6 \mathrm{c}, \mathrm{g}, \mathrm{k}$ show the same as was found by Hogan et al. (2006): that $Z_{h}$ calculated using the Brown and Francis (1995) relationship applied to aircraft-measured size spectra agrees well with radar measurements over three orders of magnitude of $Z_{h}$. Because Rayleigh-scattering $Z_{h}$ is simply proportional to the mass of the particles squared, this confirms the validity of this relationship for stratiform ice clouds, at least for the larger particles in the distribution to which the radar is sensitive. A reliable independent measure of bulk IWC was unfortunately not available on the aircraft for comparison. The dotted lines correspond to changing the mass of each particle by a factor of 2 , but the radar measurements are nearly always much closer to the line corresponding to the Brown and Francis (1995) relationship.

Figures $6 \mathrm{~b}, \mathrm{f}, \mathrm{j}$ show the corresponding fields of $Z_{\mathrm{dr}}$ from the radar. Typical values in these clouds are around $0.5 \mathrm{~dB}$, indicating the presence of low-density ice aggregates but that are nonetheless horizontally oriented. The particles clearly cannot be randomly oriented, since 

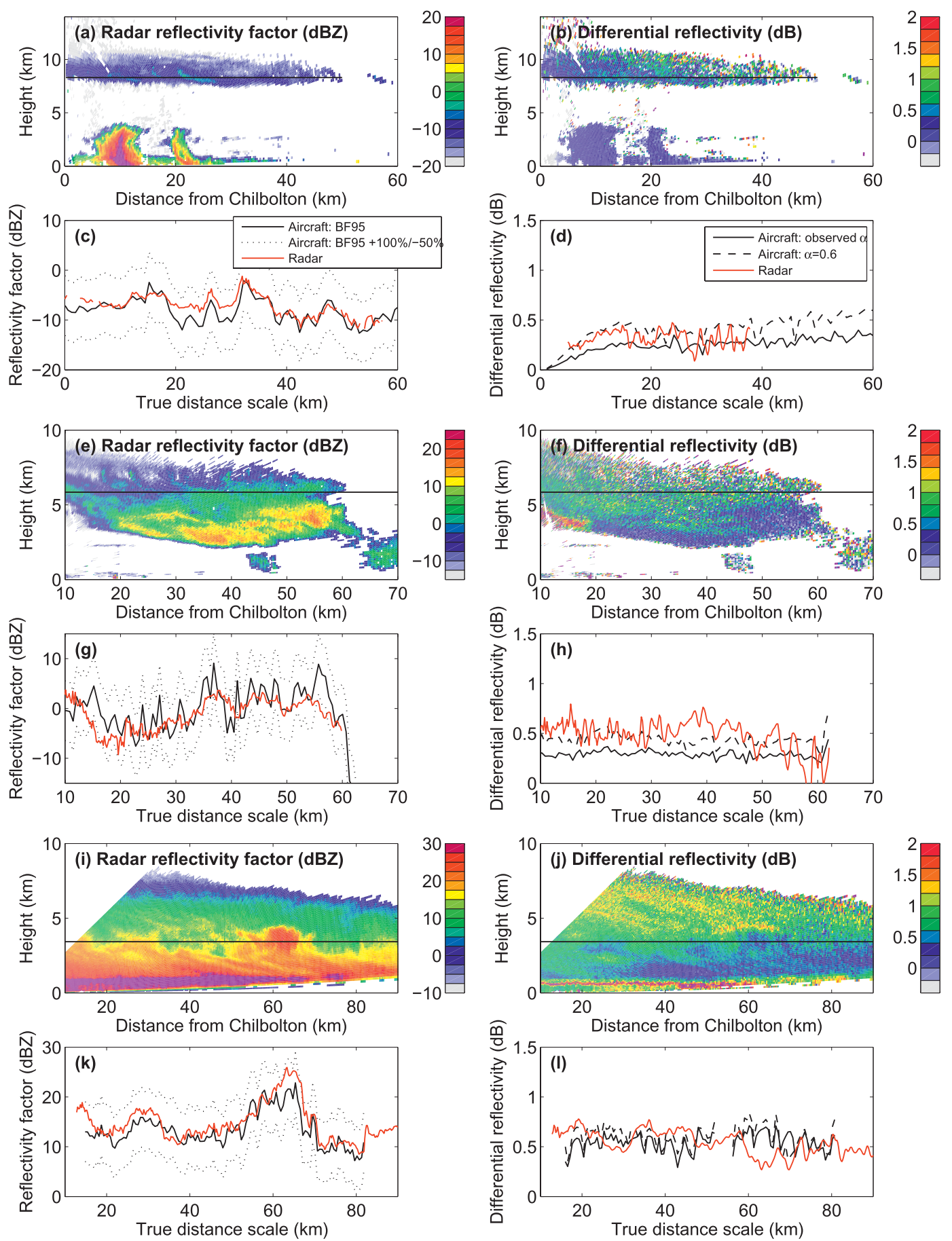

FIG. 6. (a),(b) Radar reflectivity factor $Z_{h}$ and differential reflectivity $Z_{\mathrm{dr}}$ at 1334 UTC 8 Oct 1997, where the horizontal black line indicates the altitude of the aircraft (where the temperature was $-32^{\circ} \mathrm{C}$ ); (c), (d) aircraftcalculated $Z_{h}$ and $Z_{\mathrm{dr}}$ in black [assuming the Brown and Francis (1995) mass-size relationship], with radar measurements in red. The dotted lines in (c) indicate the effect on $Z_{h}$ of doubling or halving the mass of the particles, and (d) contains two aircraft calculations: one using the measured particle axial ratios, and the other assuming $\alpha=0.6$. (e)-(h) As in (a)-(d), but at 1049 UTC 20 Oct 2000, when the aircraft was sampling at a temperature of $-24^{\circ} \mathrm{C}$. (i) -(1) As in (a)-(d), but at 1459 UTC 21 Nov 2000, when the aircraft was sampling at $-10^{\circ} \mathrm{C}$. 
that would produce $Z_{\mathrm{dr}}=0 \mathrm{~dB}$ everywhere. The tendency for $Z_{\mathrm{dr}}$ to decrease downward within the ice cloud is consistent with the larger particles having a lower density and therefore a lower $Z_{\mathrm{dr}}$ for a given axial ratio, as shown in Fig. 5. These values should be contrasted with the values above $3 \mathrm{~dB}$ that are possible in mixedphase clouds because of the rapid growth of pristine columns, plates, or dendrites in the presence of supercooled liquid water (Hogan et al. 2002, 2003).

Calibration of $Z_{\mathrm{dr}}$ has been performed in each case either by setting $Z_{\mathrm{dr}}$ to $0 \mathrm{~dB}$ at vertical incidence or by setting it to zero in very light rain (e.g., the light shower below $4 \mathrm{~km}$ in Figs. 6a,b) where the drops are spherical. Measurements at vertical incidence show a noise in $Z_{\mathrm{dr}}$ of around $\pm 0.35 \mathrm{~dB}$ at large signal-to-noise ratio (Thompson 2007), but temporal and spatial averaging allows the calibration to be constrained to around $0.1 \mathrm{~dB}(2.3 \%)$.

Figure $6 \mathrm{~d}$ compares the radar-measured $Z_{\mathrm{dr}}$ at the aircraft altitude to the values calculated from the ice particle size distributions, using both the observed particle axial ratios, and assuming a constant axial ratio of $\alpha=0.6$. The slow scan rate of $0.2^{\circ} \mathrm{s}^{-1}$ afforded modest spatial averaging, explaining why the radar measurements exhibit a noise of only around $\pm 0.1 \mathrm{~dB}$. A correction for radar elevation has been made in the aircraft calculations and is responsible for the decrease in $Z_{\mathrm{dr}}$ exhibited by the black lines for range less than approximately $20 \mathrm{~km}$, although the effect is much less significant in the other two cases. It can be seen that the radar observations generally lie between the calculated lines using the observed $\alpha$ and using a constant $\alpha=0.6$. The difference between the two calculated lines is simply because, in this case, the observed particles had $\alpha \simeq$ 0.75 , on average. In the second case in Fig. $6 \mathrm{~h}$, the radar observations are closer to the $\alpha=0.6$ line. In the third case in Fig. 61, there is much better agreement between all three lines, but in each case it should be remembered that the differences between the lines are not much larger than the expected calibration accuracy of $Z_{\mathrm{dr}}$.

Overall, these $Z_{\mathrm{dr}}$ comparisons are consistent with the use of horizontally aligned oblate spheroids with $\alpha=0.6$ as an average value in stratiform single-phase ice clouds if no other information is available, but they highlight that $\alpha$ can be systematically different from this value in individual cases. Note that $Z_{\mathrm{dr}}$ comparisons also provide support for the use of the Brown and Francis (1995) mass-size relationship; from Fig. 5 it can be seen that a doubling or halving of the mass (and hence effective density and ice fraction) of the particles would lead to a doubling or halving of $Z_{\mathrm{dr}}$ and much poorer agreement between the aircraft and radar.

\section{Application to vertically pointing millimeter- wave radar observations}

\section{a. Dependence of reflectivity factor on size, density, and axial ratio}

In this section, we explore the implications of ice particles being nonspherical for observations by nadir- or zenith-pointing millimeter-wave radar. The frequency of 94 or $95 \mathrm{GHz}$ (wavelength $3.1-3.2 \mathrm{~mm}$ ) is of particular interest as there are many radars of this frequency worldwide, and since 2006 there is one in space (Stephens et al. 2002). At this frequency, ice particles are often large enough no longer to scatter according to the Rayleigh approximation, for which only the mass is important, but in a regime where particle size is important as well. The analysis in the previous sections suggested that it is valid to treat these particles as horizontally aligned oblate spheroids with an axial ratio of approximately 0.6 , composed of a homogeneous mixture of ice and air with a mass given by (4). To rigorously calculate the scattering from such a particle illuminated by radiation with arbitrary wavelength requires a numerical approach such as the T-matrix method (Waterman 1969). For the large particles that scatter outside the Rayleigh regime, however, the density becomes very small, which means that the refractive index of the ice-air mixture is close to the value of the surrounding air. In this limit "RayleighGans" theory may be applied (e.g., van de Hulst 1957); this theory has previously been applied to snowflakes by Matrosov (1992) and Westbrook et al. (2006).

Here we use Rayleigh-Gans theory to derive an expression for oblate spheroids, and we make an improvement to represent the behavior at small sizes relative to the wavelength where the particles are dense and so classical Rayleigh-Gans theory no longer applies but the particle may still be nonspherical. A convenient analytical expression for the backscatter cross section is derived that may be used as an alternative to the much more computationally expensive T-matrix method, and comparison with this method is provided here.

Rayleigh-Gans theory assumes that the electric field within the particle may be approximated by the incident field and that radiation may be scattered only once by a volume element of the particle. In this limit, the backscatter cross section is given by (van de Hulst 1957)

$$
\sigma=\frac{k^{4}}{4 \pi}\left|\int_{-z_{\max }}^{z_{\max }} B(z) \cos (2 k z) d z\right|^{2},
$$

where $k=2 \pi / \lambda, \lambda$ is the wavelength, $z$ is the distance along the axis of the outgoing radar beam (the particle occupying the range $\pm z_{\max }$ ), and $B(z)$ is the area 
integral of $|\varepsilon-1|$ (where $\varepsilon$ is the dielectric constant of the ice-air mixture) through a slice of the particle at range $z$. For a vertically pointing radar, $z$ is a vertical coordinate, which for a horizontally aligned oblate spheroid will beparallel to its minor axis. At a particular height $z$, a horizontal slice through the particle is circular, and from geometry it can be shown that

$$
B(z)=|\varepsilon-1| \pi\left(\frac{D_{\max }^{2}}{4}-\frac{z^{2}}{\alpha^{2}}\right) .
$$

Substitution into (12) and integration yields

$$
\sigma=\frac{\pi|\varepsilon-1|^{2}}{16 k^{2} \alpha^{4}}\left[\sin \left(k D_{\text {short }}\right)-k D_{\text {short }} \cos \left(k D_{\text {short }}\right)\right]^{2} \text {. }
$$

This expression is valid only if the refractive index is close to 1 , that is, $\left|\varepsilon^{1 / 2}-1\right| \ll 1$, and if the phase shift from one side of the particle to the other is small, that is, $\left|\varepsilon^{1 / 2}-1\right| D_{\text {short }} / \lambda \ll 1$.

To verify that this approaches classical Rayleigh scattering in the limit of small particle size, we may substitute $\sin x \simeq x-x^{3} / 6$ and $\cos x \simeq 1-x^{2} / 2$ into (14) to obtain

$$
\sigma \simeq \pi^{5}|\varepsilon-1|^{2} D_{\mathrm{vol}}^{6} / 9 \lambda^{4}
$$

where $D_{\text {vol }}$ is defined by (9). This is still for the lowdensity (and hence low refractive index) limit, however; classical Rayleigh scattering predicts

$$
\sigma=\pi^{5}|K|^{2} D_{\mathrm{vol}}^{6} / \lambda^{4}
$$

where the Clausius-Mossotti factor $K$ is given by (11). We could replace $|\varepsilon-1|$ in (14) by $3|K|$ to obtain an expression that is valid both for small particles (for which the density may be large but the particles are much smaller than the wavelength) and large particles (for which the particles are large but the density is small). The problem is that classical Rayleigh scattering is applicable to spheres only, whereas we wish to retain the capability of representing small nonspherical particles for which the density may not be strictly small. In section 4, the Gans (1912) extension to Rayleigh theory was introduced for calculating the scattering by small nonspherical particles, which we may use here. It should be stressed that this is not the same as what is commonly called Rayleigh-Gans theory and has been described in this section; both Lord Rayleigh and Richard Gans worked on a wide range of scattering theories. The appropriate replacement of $|\varepsilon-1|$ in (14) is the term in vertical bars in (7), yielding what we will refer to as modified Rayleigh-Gans theory:

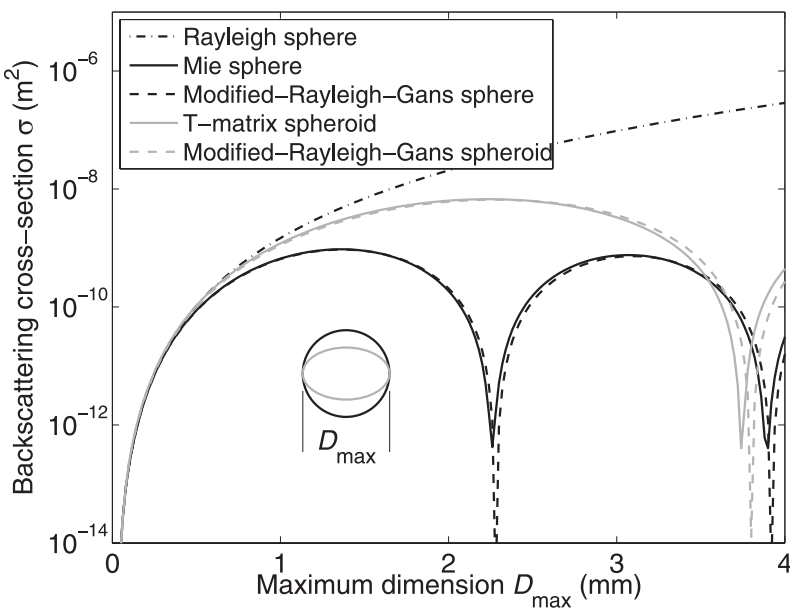

FIG. 7. Comparison of calculations of the $94-\mathrm{GHz}$ backscatter cross section for ice particles of a given maximum dimension $D_{\max }=$ $D_{\text {long, }}$ which is related to a common particle mass through (4). The black lines indicate calculations for spheres with diameter $D_{\max }$ using the Rayleigh approximation, Mie theory, and modified RayleighGans theory given by (15) with $\alpha=1$. The gray lines are for horizontally aligned oblate spheroids with axial ratio 0.6 viewed by a nadir- or zenith-pointing radar.

$$
\begin{aligned}
\sigma= & \frac{\pi}{16 k^{2} \alpha^{4}}\left|\frac{\varepsilon-1}{1+(\varepsilon-1) L^{\prime}}\right|^{2}\left[\sin \left(k D_{\text {short }}\right)\right. \\
& \left.-k D_{\text {short }} \cos \left(k D_{\text {short }}\right)\right]^{2},
\end{aligned}
$$

where the geometric factor $L^{\prime}$ is defined by (10) as before. For a sphere, $L^{\prime}=1 / 3$, in which case it may be shown that (15) does indeed simplify to the expression for Rayleigh theory as $k D_{\text {short }} \rightarrow 0$. The condition for validity of this expression is that either the particle is small relative to the wavelength $\left(D_{\text {short }} \ll \lambda\right)$ or the refractive index is small $\left(\left|\varepsilon^{1 / 2}-1\right| \ll 1\right)$. The additional condition on the phase shift across the particle still remains $\left(\left|\varepsilon^{1 / 2}-1\right| D_{\text {short }} / \lambda \ll 1\right)$. Radar reflectivity factor may be calculated by summing over all the particles in a unit volume, as given by (6).

To test (15) for the conditions appropriate to ice particles, it has been compared with Mie calculations for ice-air spheres and T-matrix calculations for oblate spheroids with $\alpha=0.6$. The results are shown in Fig. 7. In each case, the size is characterized by $D_{\max }$ and (4) is applied to estimate particle mass. Therefore, at a particular value of $D_{\max }$ each line corresponds to the same particle mass. For the spheroids, however, the same mass is concentrated in a smaller volume and therefore the density of the ice-air mixture is larger by a factor of $1 / \alpha$. At small sizes, in order that the first part of (4) is still satisfied and that the density does not exceed the value for solid ice, it is necessary to increase the axial ratio toward unity. Comparing first the Rayleigh with 
the Mie calculation, we see the large difference in backscattering that was exploited by Sekelsky et al. (1999) and Hogan et al. (2000) to estimate particle size from dualwavelength radar. The modified Rayleigh-Gans result is shown by the black dashed line and appears to match the Mie calculation closely up to $D_{\max } \simeq 2 \mathrm{~mm}$, but the subsequent minima appear to occur at slightly too large of a size. These minima occur when the scattering from the near half of the particle almost completely destructively interferes with the scattering from the far half of the particle. The speed of the electromagnetic wave is slightly retarded in the ice-air mixture, an effect that is not represented in Rayleigh-Gans theory, resulting in this slight misplacement. This is associated with the phase shift across the particle $\left|\varepsilon^{1 / 2}-1\right| D_{\text {short }} / \lambda$ not being exactly zero.

We next consider the result for oblate spheroids with an axial ratio of 0.6. It can be seen that the backscatter cross section is closer to the Rayleigh scattering result than to Mie scattering for $D_{\max }$ up to around $2.5 \mathrm{~mm}$. This implies that Mie theory would overestimate the dual-wavelength ratio for radar combinations involving 94-GHz radars by at least a factor of 2 . The modified Rayleigh-Gans theory again compares very well to the more exact T-matrix computation and again exhibits a slight misplacement of the minima. It is clear from (15) that the locations of the minima are entirely determined by $D_{\text {short }}$, and it should be stressed that the misplacement is smaller than the uncertainty in the value of $D_{\text {short }}$ for a given particle (see the range of different axial ratios evident from Figs. 2 and 6), and therefore modified Rayleigh-Gans theory can be used with confidence for this problem. The reason that the value of $D_{\max }$ at the first minimum differs by a factor of 0.6 between the calculations assuming spheres and spheroids is simply because these are the points at which $D_{\text {short }}$ has its critical value of around $2.3 \mathrm{~mm}$, where there is maximum destructive interference.

\section{b. Case study}

The investigation of whether oblate spheroids are a better model than spheres for ice particle scattering at $94 \mathrm{GHz}$ is facilitated by the use of two radar wavelengths, one at $94 \mathrm{GHz}$ and the other at a Rayleigh-scattering wavelength, that are observing a cloud simultaneous to its being sampled in situ. Matrosov et al. (2005a) took this approach using data taken in the Cirrus Regional Study of Tropical Anvils and Cirrus Layers-FloridaArea Cirrus Experiment (CRYSTAL-FACE) in 2002. Here we use data from the same two aircraft but obtained during the Tropical Composition, Cloud and Climate Coupling (TC4) experiment in Costa Rica in 2007. Figure 8 shows observations by the $10-$ and $94-\mathrm{GHz}$ radars on board the National Aeronautics and Space Administration (a) $94-\mathrm{GHz}$ radar reflectivity factor (dBZ)

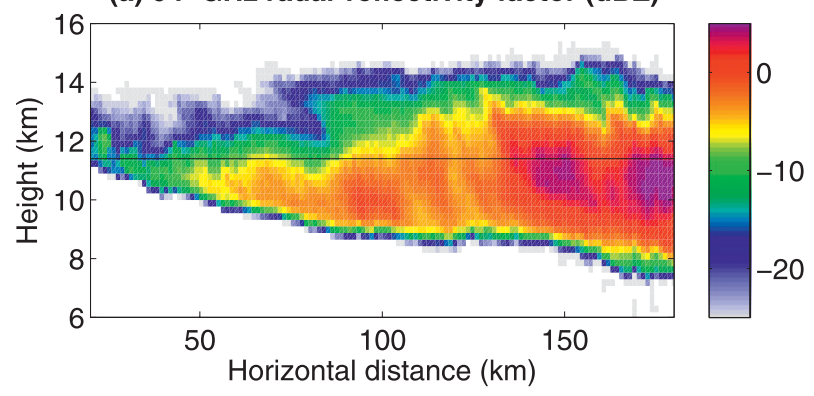

(b) Dual-wavelength ratio (dB)

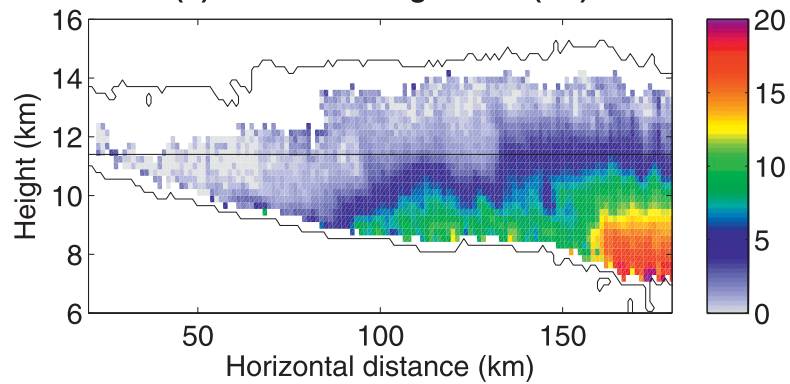

FIG. 8. (a) Radar reflectivity factor observed by the $94-\mathrm{GHz}$ Cloud Radar System (CRS) on the NASA ER-2 aircraft from an altitude of $20 \mathrm{~km}$ between 1423 and 1439 UTC 31 Jul 2007. (b) Corresponding ratio of reflectivity factor observed by the $10-\mathrm{GHz}$ ER-2 Doppler radar (EDOP) to that measured by CRS, where the black contour indicates the cloud boundary observed by the moresensitive CRS. The horizontal line in each panel corresponds to the altitude of the DC-8 aircraft.

(NASA) high-altitude ER-2 aircraft. Figure 8a depicts the radar reflectivity factor observed by the $94-\mathrm{GHz}$ radar in a thick cirrus cloud, and Fig. $8 \mathrm{~b}$ shows the dual-wavelength ratio, defined as

$$
\operatorname{DWR}=10 \log _{10}\left(Z_{10} / Z_{94}\right),
$$

where $Z_{f}$ is the radar reflectivity factor at frequency $f$. The $94-\mathrm{GHz}$ radar has been calibrated to better than $1 \mathrm{~dB}$ as described by Li et al. (2004), while the $10-\mathrm{GHz}$ radar (Heymsfield et al. 1996) is calibrated to the other by matching the radar reflectivities at cloud top where the ice particles are assumed to be Rayleigh scattering at both frequencies (e.g., Hogan et al. 2000). By this method we expect DWR to be accurate to better than $0.5 \mathrm{~dB}$ in this case. If we treat the particles as spheres then, according to Fig. 7, the dual-wavelength ratios of greater than $10 \mathrm{~dB}$ toward cloud base indicate the presence of particles in excess of $1.5 \mathrm{~mm}$ in diameter, whereas treatment of them as horizontally aligned oblate spheroids with an axial ratio of 0.6 would indicate the presence of particles with a longest dimension in excess of $2.5 \mathrm{~mm}$ and hence a shortest (vertical) dimension of $1.5 \mathrm{~mm}$. 
Underflying the ER-2 was the DC-8 aircraft, making simultaneous in situ measurements of the size distributions at $11.4 \mathrm{~km}$ where the temperature was approximately $-47^{\circ} \mathrm{C}$. This aircraft is equipped with a $2 \mathrm{D}$ Cloud Imaging Probe (CIP) and a Precipitation Imaging Probe (PIP). The CIP measured particle size from about 50 100 micrometers to above $1 \mathrm{~mm}$, and the PIP measured particle size from about 100 micrometers to $6.2 \mathrm{~mm}$. The size distributions were binned by $D_{\max }$. It was found by Tian et al. (2010) in this case that the IWC estimated by the Brown and Francis (1995) relationship agreed well with direct measurements by the counterflow virtual impactor (CVI), but only when applied to $D_{\max }$ rather than $D_{\text {mean }}$. This implies that, if applied to $D_{\text {mean }}$ as recommended in earlier sections, the IWC would be underestimated by approximately one-third.

Figure 9 compares the radar observations at the altitude of the DC- 8 (gray lines) with the values calculated using the in situ probes by that aircraft (black lines). The black solid lines show Mie calculations that treat the particles as homogeneous spheres of diameter $D_{\max }$ with mass given by the Brown and Francis (1995) relationship in (2), but using $D_{\max }$ instead of $D_{\text {mean }}$. Figure 9a reveals that this leads to Rayleigh-scattering radar reflectivity factor being overestimated by approximately $5 \mathrm{~dB}$. A similar error is found at $94 \mathrm{GHz}$ in Fig. 9b for $Z_{94}<-5 \mathrm{~dB} Z$, where presumably the particles are small enough to be scattering close to the smallparticle (i.e., Rayleigh) limit. For $Z_{94}>-5 \mathrm{~dB} Z$, where the particles are large enough to scatter outside this limit, the agreement appears to be improved. Figure 9c shows that, for horizontal distances greater than $100 \mathrm{~km}$ for which the particles are larger, the spherical assumption leads to DWR being overestimated by approximately a factor of 2 .

We now consider the black dashed lines, which show calculated radar variables with the assumption that ice particles are horizontally aligned oblate spheroids with an axial ratio of 0.6 , a long-axis dimension of $D_{\max }$, and a mass given by the Brown and Francis (1995) relationship but first using (3) to convert from $D_{\max }$ to $D_{\text {mean }}$. Figure 9 a shows that this reduces $Z_{10}$ by $3.7 \mathrm{~dB}$, as predicted in section 2 , leading to considerably closer agreement with the radar observations. At $10 \mathrm{GHz}$ we are in the small-particle limit, and therefore this difference is purely due to the reduction in particle mass (had we used spheroids with mass computed using $D_{\text {max }}$, the result would have been very close to the black solid line). There is still a residual difference of $1-2 \mathrm{~dB}$ between the gray and dashed black lines, but this is more easy to explain by either a radar calibration error, or a modest deviation from the Brown and Francis (1995) relationship in this particular cloud (a deviation

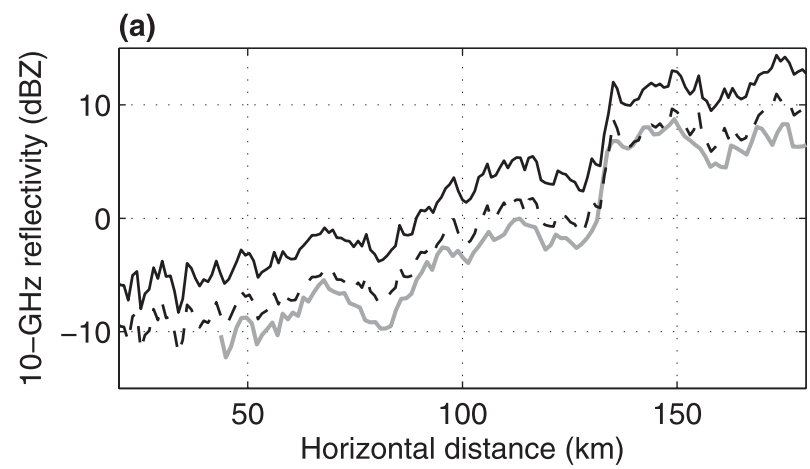

(b)
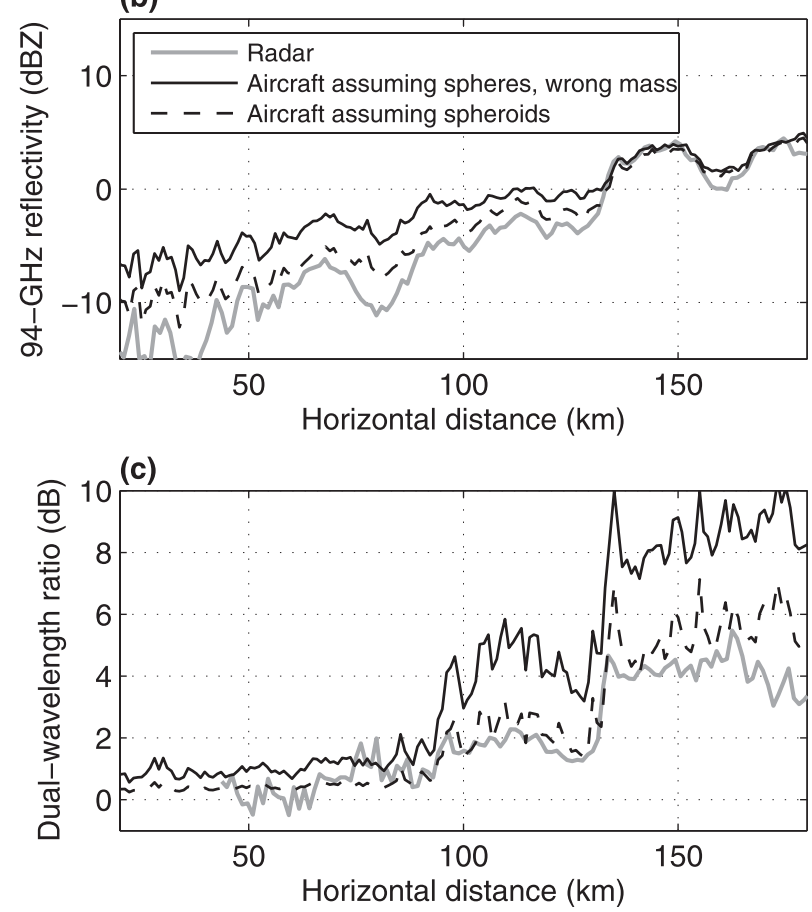

FIG. 9. Comparison of measurements by the ER-2 radars from Fig. 8 (gray lines) and calculations from the coincident in situ measurements of the DC-8 aircraft. The black solid lines show calculations that treat the ice particles as spheres with a diameter of $D_{\max }$ and with application of the Brown and Francis (1995) formula given by (2) but incorrectly assuming $D_{\text {mean }}=D_{\text {max }}$, and the black dashed lines show calculations that treat the particles as horizontally oriented oblate spheroids with an axial ratio of 0.6 and a mass given by (4).

of around the same magnitude was observed in the opposite sense in Fig. 6k).

Figure $9 \mathrm{~b}$ shows somewhat better agreement for oblate spheroids than for spheres where $Z_{94}<0 \mathrm{~dB} Z$. Here the particles are smaller and so the shape has little effect, and this change is occurring for the same reason as in Fig. 9a for $Z_{10}$. In the region where $Z_{94}>0 \mathrm{~dB} Z$, the particles are larger and so both their mass and shape are important. The fact that $Z_{94}$ is essentially unchanged may be explained by the fact that the reduced particle 
mass leads to a decrease in $Z_{94}$ while the use of oblate spheroids leads to an increase in $Z_{94}$. Thus, the good agreement that was previously found between the spherical assumption and the radar observations in this region is likely to be due to a cancellation of errors.

Figure 9c shows that calculated DWR is considerably reduced by the use of oblate spheroids, bringing it much closer to the radar observations. Very similar results were found by Matrosov et al. (2005a), who also considered oblate spheroids with an axial ratio of 0.6. By taking the ratio of reflectivity factors, the effect of particle density and absolute radar calibration has been removed and so DWR is essentially a function of size and shape alone; specifically it is a measure of the dimension of the particle in the direction that the radar is pointing (Hogan et al. 2000). Because DWR scales approximately with axial ratio, the remaining slight overestimate in Fig. 9c could be remedied by using an axial ratio of 0.5 . The radar observations have an error of approximately $0.5 \mathrm{~dB}$ from the cross calibration of the two radars, however, and therefore further work would be required before an axial ratio lower than 0.6 [which is already at the lower end of the 0.6-0.65 range found by Korolev and Isaac (2003) and Westbrook et al. (2004)] could be recommended.

Last, we comment on the fact that despite the Brown et al. (1995) relationship predicting radar reflectivity factors that are in reasonable agreement with observations it underpredicts IWC by approximately one-third. This could partially be explained by the fact that particles smaller than $100 \mu \mathrm{m}$ were not used in the analysis, but there still appears to be an outstanding problem that mass-size relationships derived to provide the best fit with CVI observations of IWC (e.g., Heymsfield et al. 2010) are not consistent with the mass-size relationship that provides the best fit with radar observations of reflectivity factor. This problem was first reported by Heymsfield et al. (2005), who used the same ER-2 and DC-8 aircraft but in the earlier CRYSTAL-FACE experiment to show that the mass $-D_{\max }$ relationship that best predicted the IWC from the CVI led to an overestimate in $Z_{10}$ of around $5 \mathrm{~dB}$. Further discussion of this matter is provided in section 7 .

\section{Implications for estimating ice water content from radar}

The dual-wavelength radar results of the previous section illustrate that even if the mass of an ice particle is known its $94-\mathrm{GHz}$ reflectivity factor for a vertically pointing radar will be greatly underestimated if it is assumed to scatter as a sphere with a diameter equal to its longest dimension. This bias increases with particle size
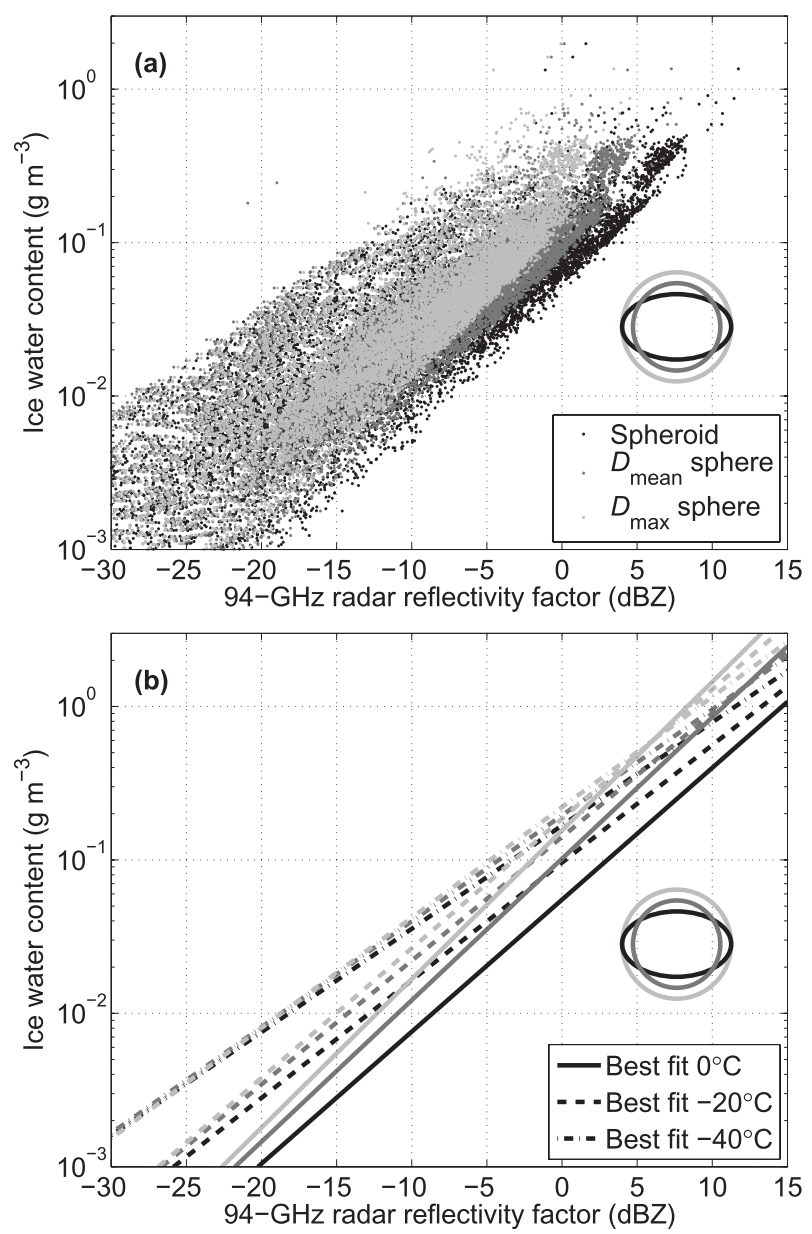

FIG. 10. (a) Scatterplots of IWC vs $Z_{94}$ calculated using aircraft size distributions measured during EUCREX. The three shades indicate different assumptions on the shape of the particle in calculating $Z_{94}$, although the particle masses and hence the IWC are the same in each case. (b) Empirical $\operatorname{IWC}\left(Z_{94}, T\right)$ fits to the data in (a) at three temperatures using the method of Hogan et al. (2006).

and has important implications for radar retrieval algorithms for ice clouds. To illustrate this we recalculate the Hogan et al. (2006) empirical formula for estimating IWC from $94-\mathrm{GHz}$ radar reflectivity factor and temperature, using different assumptions on ice particle shape.

The original Hogan et al. (2006) calculations were performed using size distributions from the European Cloud Radiation Experiment (EUCREX) binned by $D_{\text {mean }}$ with particle mass estimated using (2). For estimating reflectivity factor, the particles were treated as spheres with diameter $D_{\text {mean }}$, and the resulting 5-s averaged IWC and $Z_{94}$ values are shown by the dark-gray dots in Fig. 10. Note that Liu and Illingworth (2000) used the same dataset and made the same assumptions. The black and light-gray dots show the effect of different assumptions on ice particle shape, but keeping the same 
mass. Therefore, IWC is unchanged and the dots move only to the left or right. The light-gray dots show calculations in which the particles are treated as spheres of diameter $D_{\max }$. For the highest values of IWC it can be seen that this reduces $Z_{94}$ from the Hogan et al. (2006) dots by approximately $3 \mathrm{~dB}$. At the other extreme, the black dots show calculations in which the particles are treated as horizontally aligned oblate spheroids with an axial ratio of 0.6 and viewed by a vertically pointing radar (either from above or below). From the evidence presented in sections 4 and 5 of this paper, we argue that this is the best model for ice particle scattering at $94 \mathrm{GHz}$. For the highest IWC values, this increases $Z_{94}$ by approximately $3 \mathrm{~dB}$ from the Hogan et al. (2006) [and therefore Liu and Illingworth (2000)] points and by approximately $6 \mathrm{~dB}$ from the spheres with diameter $D_{\text {max }}$. Matrosov and Heymsfield (2008) also compared $Z_{94}$ calculated from aircraft size distributions assuming spheres and assuming spheroids with $\alpha=0.6$ and found a difference of up to $4 \mathrm{~dB}$, although their dataset included more high- $Z$ clouds than the EUCREX dataset used here.

We have repeated exactly the method of Hogan et al. (2006) to calculate an $\operatorname{IWC}\left(Z_{94}, T\right)$ relationship but assuming the particles to be oblate spheroids and calculating their backscatter coefficient using the T-matrix method. The resulting expression for the expected value of IWC is

$$
\begin{aligned}
\log _{10}(\mathrm{IWC})= & 0.000472 Z_{94} T-0.0114 T \\
& +0.0867 Z_{94}-1.22
\end{aligned}
$$

where IWC has the units of grams per meter cubed, $Z_{94}$ is in decibels $(\mathrm{dBZ})$, and temperature $T$ is in degrees Celsius. For comparison, Matrosov and Heymsfield (2008) also fitted a power law to aircraft data assuming oblate spheroids with $\alpha=0.6$ but chose to neglect any temperature dependence and also to consider clouds with $Z_{94}>0 \mathrm{dBZ}$. Their relationship had the form IWC $\left(\mathrm{g} \mathrm{m}^{-3}\right)=0.086 Z_{94}^{0.92}\left(\mathrm{~mm}^{6} \mathrm{~m}^{-3}\right)$. In the range $0-$ $10 \mathrm{~dB} Z$, that is, where their fit is valid and where EUCREX has data, their expression agrees with ours to within $\pm 15 \%$ for $T=-20^{\circ} \mathrm{C}$, and the two expressions predict the same IWC at $Z_{94}=5 \mathrm{~dB} Z$.

Figure 10 depicts the corresponding best estimate of IWC from $Z_{94}$ at three temperatures, not only for the new oblate spheroid model (black lines), but also from the original Hogan et al. (2006) $D_{\text {mean }}$ spheres (darkgray lines) and the lines that would be fitted for $D_{\max }$ spheres (light-gray lines). For $Z_{94}=10 \mathrm{~dB} Z$ and temperature close to $0^{\circ} \mathrm{C}$, there is a factor-of- 4 difference in the IWC values that would be retrieved for the $D_{\max }$ spheres and the oblate spheroids and closer to a factor-of-2 difference between $D_{\text {mean }}$ spheres and oblate spheroids. In principle, any IWC retrieval scheme that makes use of $94-\mathrm{GHz}$ radar reflectivity factor in ice clouds and makes the spherical assumption could be subject to this kind of error in the thickest clouds. Whether the error is a factor of 2 or 4 depends on how the scheme has been formulated. For example, Stein et al. (2011) evaluated two versions of the variational Delanoë and Hogan (2010) satellite radar and lidar retrieval, one assuming spheres with diameter $D_{\text {mean }}$ in the radar forward model and the other assuming oblate spheroids. Almost a factor-of-2 difference in retrieved IWC was found in clouds with $Z_{94} \simeq 10 \mathrm{dBZ}$. The standard Delanoë and Hogan (2010) product now assumes oblate spheroids for radar scattering, and better agreement was found with large-scale models in the thickest clouds (Delanoë et al. 2011).

\section{Discussion and conclusions}

In this paper we have hypothesized that, in singlephase ice clouds (both stratiform frontal cloud and cirrus anvils), radar scattering is best modeled by treating the particles as horizontally aligned oblate spheroids with an axial ratio of 0.6 , consisting of a homogeneous mixture of ice and air with a relationship between particle mass and "mean dimension" $D_{\text {mean }}$ given by Brown and Francis (1995). Coincident radar and aircraft observations have then been used to test these assumptions in three different ways. Comparison of centimeter-wavelength radar reflectivity between aircraft and radar measurements tests the mass assumption. Comparison of centimeterwavelength differential reflectivity is sensitive to the assumed particle axial ratio and density, but for fixed axial ratio and density it is independent of particle size. Comparison of dual-wavelength ratio calculated from zenith- or nadir-pointing centimeter- and millimeter-wave radars is sensitive to particle axial ratio and particle size but is independent of particle mass or density.

In agreement with Hogan et al. (2006), we find that the Brown and Francis (1995) relationship is able to predict Rayleigh-scattering reflectivity factor with a mean error for each aircraft run of the order of $1 \mathrm{~dB}$ or less. The importance of applying their mass-size relationship to the right measure of particle size is highlighted when we follow several studies in the literature and apply it to the maximum particle dimension $D_{\text {max }}$ instead of $D_{\text {mean }}$, which leads to an overestimate of $Z$ by around $3.7 \mathrm{~dB}$. Equation (4) provides the Brown and Francis (1995) relationship but for ice size distributions binned by $D_{\max }$.

Comparison of differential reflectivity and dualwavelength ratio supports the use of an axial ratio of 0.6, in agreement with the findings of Matrosov et al. (2005a). 
The fact that the simple homogeneous oblate spheroid model works well in most ice clouds is very convenient and suggests that there is no need to use more sophisticated scattering calculations on more complex ice particle shapes. Despite the good performance of $\alpha=0.6$, we have found evidence of deviations from this value in individual aircraft runs. For example, part of the tenuous midlatitude cirrus observed in Figs. 6a-d would be better fitted assuming an axial ratio of 0.75 , whereas the thickest part of the tropical cirrus in Figs. 8 and 9 at horizontal distances greater than $130 \mathrm{~km}$ would be slightly better fitted assuming an axial ratio of 0.5. These differences could be due to the weak size dependence of axial ratio suggested in Fig. 4, but further radar evidence would be required to justify using an axial ratio varying with size.

Our results are consistent with the findings reported by Korolev et al. $(1999,2000)$ that most ice particles are irregular and with the work of Westbrook et al. (2004, 2007) suggesting that this is due to the dominance of the aggregation process (at least for the larger particles to which the radar is sensitive) over a wide range of temperatures. This could then explain why an axial ratio of approximately 0.6 appears to fit the observations satisfactorily from a diverse range of clouds.

There is a need for further work to resolve the problem that no single mass-size relationship appears able to predict both IWC and radar reflectivity factor simultaneously, at least in comparison with current state-of-theart independent measurements of these variables. This is the case for the cloud observed in section 5 but was also found in a larger dataset by Heymsfield et al. (2005). Heymsfield et al. (2010) derived a relationship between mass and $D_{\max }$ that was found to provide the best agreement with an independent estimate of IWC from the CVI, but this relationship predicts IWC of approximately $45 \%$ more than Brown and Francis (1995) when applied to the EUCREX dataset. We would expect the CVI to be much more reliable than the Lyman- $\alpha$ instrument used by Brown and Francis (1995) to estimate IWC. Heymsfield et al. (2010) actually reported that the Brown and Francis (1995) relationship performed reasonably well in comparison with the CVI, but this result now seems likely to be because this $45 \%$ underestimate was countered by the approximately $53 \%$ overestimate that is due to Heymsfield et al. (2010) applying the original expression (2) to $D_{\max }$ rather than $D_{\text {mean }}$ (see section 2 for a full discussion of this effect). This implies that the Brown and Francis (1995) relationship underestimates ice particle mass, but in Figs. 6 and 9a it was found to perform very well in estimating Rayleigh-scattering reflectivity factor, where particle mass is the only important property, over three orders of magnitude (from -20 to +10 dBZ). Applying instead the Heymsfield et al. (2010) relationship to the EUCREX dataset, we find that it predicts Rayleigh reflectivity to be $2.5 \mathrm{~dB}$ higher than Brown and Francis (1995) at $-20 \mathrm{dBZ}$, rising to $6.5 \mathrm{~dB}$ higher at $+10 \mathrm{dBZ}$. This is consistent with the $5-\mathrm{dB}$ error reported by Heymsfield et al. (2005) when comparing radar measurements and aircraft calculations using the same two aircraft as in section 5. It unfortunately seems to be impossible to find one mass-size relationship that fits both IWC and reflectivity factor without accepting a much greater error in the calibration of either the radars or the aircraft instruments than would reasonably be expected.

Further work is also required to characterize ice particle mass and axial ratio in certain types of clouds. Our results are limited to single-phase clouds, whereas the observations of Hogan et al. $(2002,2006)$ show that in the presence of supercooled liquid water, deposition dominates over aggregation leading to ice particles with a higher density than predicted by Brown and Francis (1995), and more extreme axial ratio than 0.6. Conversely, in the cores of convective clouds one would expect riming to lead to particles that are denser and more spherical than those produced by aggregation. Furthermore, the aircraft probes used in this study were not able to measure snowflakes larger than around $0.5 \mathrm{~cm}$ in diameter, so our findings are limited to smaller particles than this. It can be difficult to achieve radar and aircraft observations to better than $1 \mathrm{~km}$ for an entire run, yet this is essential if scattering models are to be validated for the full range of real ice clouds.

Acknowledgments. We thank Dr. Paul Field for assistance in processing some of the ice particle size distributions in section 4 and Dr. Aaron Bansemer for processing the DC-8 data in section 5. Author LT thanks Drs. Gerry Heymsfield and Lihua Li for discussions on airborne radar calibration and engineer support. RJH thanks Dr. Anthony Illingworth for discussions on Chilbolton radar calibration. The contributions of RJH and CDW were supported by NERC Grant NE/H003894/1, and LT is funded by the NASA Precipitation Measurement Mission. Financial support was provided to AJH by NASA Awards NX07AQ85G and NNX08AH57G (through Hal Maring).

\section{APPENDIX}

\section{Fitting an Ellipse to an Ice Particle Image}

In this appendix it is shown how an ellipse may be fitted to an ice particle image to determine the longest and shortest dimensions $D_{\text {long }}$ and $D_{\text {short }}$, as illustrated in Fig. 1. This is used in the calculation of differential reflectivity in section 4 . 
For the image being analyzed, two sets of numbers, $x$ and $y$, are defined that contain the array-perpendicular and array-parallel coordinates of each shadowed diode (corresponding to the along-track and across-track directions, respectively). Hence the "center of gravity" is at $(\bar{x}, \bar{y})$. The vectors are first normalized so that the center of gravity lies at $(0,0)$. We need to find the major axis of the image, such that the sum of the squares of the shortest distance from every shadowed diode to this axis is minimized. If the major axis is defined by $y=m x$, then it can be shown that the closest distance from it to the point $\left(x_{i}, y_{i}\right)$ is given by

$$
l_{i}=\left(\frac{m^{2} x_{i}^{2}}{m^{2}+1}+\frac{y_{i}^{2}}{m^{2}+1}-\frac{2 x_{i} y_{i}}{m+1 / m}\right)^{1 / 2} .
$$

The unknown $m$ can be found by solving

$$
\frac{d}{d m} \sum_{i=1}^{N} l_{i}^{2}=0
$$

The solution is

$$
m=-\gamma \pm\left(\gamma^{2}+1\right)^{1 / 2},
$$

where $\gamma=\left(\overline{x^{2}}-\overline{y^{2}}\right) /(2 \overline{x y})$. Equation (A3) provides the gradients of both the major and minor axes (selected via the " \pm " term). The shortest dimension $D_{\text {short }}$ is determined to be the distance between the major axis and the center of the pixel that lies farthest from the axis on one side, plus the distance from the axis to the farthest pixel on the other side, plus the width of one pixel. The longest dimension $D_{\text {long }}$ is defined equivalently for the minor axis.

\section{REFERENCES}

Austin, R. T., A. J. Heymsfield, and G. L. Stephens, 2009: Retrieval of ice cloud microphysical parameters using the CloudSat millimeter-wave radar and temperature. J. Geophys. Res., 114, D00A23, doi:10.1029/2008JD010049.

Bader, M. J., S. A. Clough, and G. P. Cox, 1987: Aircraft and dual polarization radar observations of hydrometeors in light stratiform precipitation. Quart. J. Roy. Meteor. Soc., 113, 491-515.

Brown, P. R. A., and P. N. Francis, 1995: Improved measurements of the ice water content in cirrus using a total-water probe. J. Atmos. Oceanic Technol., 12, 410-414.

—, A. J. Illingworth, A. J. Heymsfield, G. M. McFarquhar, K. A. Browning, and M. Gosset, 1995: The role of spaceborne millimeter-wave radar in the global monitoring of ice cloud. J. Appl. Meteor., 34, 2346-2366.

Delanoë, J., and R. J. Hogan, 2008: A variational scheme for retrieving ice cloud properties from combined radar, lidar, and infrared radiometer. J. Geophys. Res., 113, D07204, doi:10.1029/ 2007JD009000.
— and - 2010: Combined CloudSat-CALIPSO-MODIS retrievals of the properties of ice clouds. J. Geophys. Res., 115, D00H29, doi:10.1029/2009JD012346.

,,-- R. M. Forbes, A. Bodas-Salcedo, and T. H. M. Stein, 2011: Evaluation of ice cloud representation in the ECMWF and UK Met Office models using CloudSat and CALIPSO data. Quart. J. Roy. Meteor. Soc., 137, 2064-2078.

Donovan, D. P., and Coauthors, 2001: Cloud effective particle size and water content profile retrievals using combined lidar and radar observations 2. Comparison with IR radiometer and in situ measurements of ice clouds. J. Geophys. Res., 106, 27 44927464.

— M. Quante, I. Schlimme, and A. Macke, 2004: Use of equivalent spheres to model the relation between radar reflectivity and optical extinction of ice cloud particles. Appl. Opt., 43, 4929-4940.

Gans, R., 1912: Über die Form ultramikroskipischer Goldteilchen (On the shape of ultra-microscopic gold particles). Ann. Phys., 37, 881-900.

Goddard, J. W. F., J. Tan, and M. Thurai, 1994: Technique for calibration of meteorological radars using differential phase. Electron. Lett., 30, 166-167.

Gourley, J. J., A. J. Illingworth, and P. Tabary, 2009: Absolute calibration of radar reflectivity using redundancy of the polarization observations and implied constraints on drop shapes. J. Atmos. Oceanic Technol., 26, 689-703.

Hall, M. P. M., J. W. F. Goddard, and S. M. Cherry, 1984: Identification of hydrometeors and other targets by dual-polarization radar. Radio Sci., 19, 149-163.

Heymsfield, A. J., A. Bansemer, C. Schmitt, C. Twohy, and M. R. Poellot, 2004: Effective ice particle densities derived from aircraft data. J. Atmos. Sci., 61, 982-1003.

— Z Z. Wang, and S. Y. Matrosov, 2005: Improved radar ice water content retrieval algorithms using coincident microphysical and radar measurements. J. Appl. Meteor., 44, 1391-1412.

—, G.-J. van Zadelhoff, D. P. Donovan, F. Fabry, R. J. Hogan, and A. J. Illingworth, 2007: Refinements to ice particle mass dimensional and terminal velocity relationships for ice clouds. Part II: Evaluation and parameterizations of ensemble ice particle sedimentation velocities. J. Atmos. Sci., 64, 10681088.

— C. Schmitt, A. Bansemer, and C. H. Twohy, 2010: Improved representation of ice particle masses based on observations in natural clouds. J. Atmos. Sci., 67, 3303-3318.

Heymsfield, G. M., and Coauthors, 1996: The EDOP radar system on the high-altitude NASA ER-2 aircraft. J. Atmos. Oceanic Technol., 13, 795-809.

Hogan, R. J., and A. J. Illingworth, 1999: The potential of spaceborne dual-wavelength radar to make global measurements of cirrus clouds. J. Atmos. Oceanic Technol., 16, 518-531.

,-- , and H. Sauvageot, 2000: Measuring crystal size in cirrus using 35- and 94-GHz radars. J. Atmos. Oceanic Technol., 17, 27-37.

- , P. R. Field, A. J. Illingworth, R. J. Cotton, and T. W. Choularton, 2002: Properties of embedded convection in warm-frontal mixed-phase cloud from aircraft and polarimetric radar. Quart. J. Roy. Meteor. Soc., 128, 451-476.

, P. N. Francis, H. Flentje, A. J. Illingworth, M. Quante, and J. Pelon, 2003: Characteristics of mixed-phase clouds. I: Lidar, radar and aircraft observations from CLARE'98. Quart. J. Roy. Meteor. Soc., 129, 2089-2116.

_ M. P. Mittermaier, and A. J. Illingworth, 2006: The retrieval of ice water content from radar reflectivity factor and 
temperature and its use in the evaluation of a mesoscale model. J. Appl. Meteor. Climatol., 45, 301-317.

Illingworth, A. J., and Coauthors, 2007: Cloudnet: Continuous evaluation of cloud profiles in seven operational models using groundbased observations. Bull. Amer. Meteor. Soc., 88, 883-898.

King, W. D., 1985: Air flow and particle trajectories around aircraft fuselages. Part III: Extensions to particles of arbitrary shape. J. Atmos. Oceanic Technol., 2, 539-547.

_ lages. IV: Orientation of ice crystals. J. Atmos. Oceanic Technol., 3, 433-439.

Knollenberg, R. G., 1970: The optical array: An alternative to scattering for airborne particle size determination. J. Appl. Meteor., 9, 86-103.

Korolev, A., and G. Isaac, 2003: Roundness and aspect ratio of particles in ice clouds. J. Atmos. Sci., 60, 1795-1808.

,-- , and J. Hallet, 1999: Ice particle habits in Arctic clouds. Geophys. Res. Lett., 26, 1299-1302.

,$- \ldots$, and — 2000: Ice particle habits in stratiform clouds. Quart. J. Roy. Meteor. Soc., 126, 2873-2902.

Li, L., G. M. Heymsfield, P. E. Racette, L. Tian, and E. Zenker, 2004: A 94-GHz cloud radar system on a NASA high-altitude ER-2 aircraft. J. Atmos. Oceanic Technol., 21, 1378-1388.

Liu, C.-L., and A. J. Illingworth, 2000: Toward more accurate retrievals of ice water content from radar measurements of clouds. J. Appl. Meteor., 39, 1130-1146.

Locatelli, J. D., and P. V. Hobbs, 1974: Fall speeds and masses of solid precipitation particles. J. Geophys. Res., 79, 2185-2197.

Matrosov, S. Y., 1992: Radar reflectivity in snowfall. IEEE Trans. Geosci. Remote Sens., 30, 454-461.

_ tinction in precipitating cloud systems from CloudSat radar measurements. J. Geophys. Res., 113, D00A05, doi:10.1029/ 2007JD009633.

_, R. F. Reinking, R. A. Kropfli, B. E. Martner, and B. W. Bartram, 2001: On the use of radar depolarization ratios for estimating shapes of ice hydrometeors in winter clouds. J. Appl. Meteor., 40, 479-490.

_ A. J. Heymsfield, and Z. Wang, 2005a: Dual-frequency radar ratio of nonspherical atmospheric hydrometeors. Geophys. Res. Lett., 32, L13816, doi:10.1029/2005GL023210.

— , R. F. Reinking, and I. V. Djalalova, 2005b: Inferring fall altitudes of pristine dendritic crystals from polarimetric radar data. J. Atmos. Sci., 62, 241-250.

Maxwell-Garnet, J. C., 1904: Colours in metal glasses and metallic films. Philos. Trans. Roy. Soc. London, 203, 385-420.

Mitchell, D. L., 1996: Use of mass- and area-dimensional power laws for determining precipitation particle terminal velocities. J. Atmos. Sci., 53, 1710-1723.

O'Brien, S. G., and G. H. Goedecke, 1988: Scattering of millimeter waves by snow crystals and equivalent homogeneous symmetric particles. Appl. Opt., 27, 2439-2444.

Platt, C. M. R., N. Abshire, and G. McNice, 1978: Some microphysical properties of an ice cloud from lidar observation of horizontally aligned crystals. J. Appl. Meteor., 17, 12201224.

Pruppacher, H. R., and J. D. Klett, 1997: Microphysics of Clouds and Precipitation. Springer, $954 \mathrm{pp}$.

Sassen, K., 1977: Ice crystal habit discrimination with the optical backscatter depolarization technique. J. Appl. Meteor., 16, 425-431.

Schneider, T. L., and G. L. Stephens, 1995: Theoretical aspects of modeling backscattering by cirrus ice particles at millimeter wavelengths. J. Atmos. Sci., 52, 4367-4385.

Sekelsky, S. M., W. L. Ecklund, J. M. Firda, K. S. Gage, and R. E. McIntosh, 1999: Particle size estimation in ice-phase clouds using multifrequency radar reflectivity measurements at 95 , 33, and 2.8 GHz. J. Appl. Meteor., 38, 5-28.

Seliga, T. A., and V. N. Bringi, 1976: Potential use of radar differential reflectivity measurements at orthogonal polarizations for measuring precipitation. J. Appl. Meteor., 15, 69-76.

Stein, T. H. M., J. Delanoë, and R. J. Hogan, 2011: A comparison among four different retrieval methods for ice-cloud properties using data from CloudSat, CALIPSO, and MODIS. J. Appl. Meteor. Climatol., 50, 1952-1969.

Stephens, G. L., and Coauthors, 2002: The CloudSat Mission and the A-Train. Bull. Amer. Meteor. Soc., 83, 1771-1790.

Stokes, G. M., and S. E. Schwartz, 1994: The Atmospheric Radiation Measurement (ARM) Program: Programmatic background and design of the cloud and radiation test bed. Bull. Amer. Meteor. Soc., 75, 1201-1221.

Thomas, L., J. C. Cartwright, and D. P. Wareing, 1990: Lidar observations of the horizontal orientation of ice crystals in cirrus clouds. Tellus, 42B, 211-216.

Thompson, R. J., 2007: Rainfall estimation using polarimetric weather radar. Ph.D. thesis, University of Reading, 183 pp.

Tian, L., G. M. Heymsfield, A. J. Heymsfield, A. Bansemer, L. Li, C. H. Twohy, and R. C. Srivastava, 2010: A study of cirrus ice particle size distributions using TC4 observations. J. Atmos. Sci., 67, 195-216.

van de Hulst, H. C., 1957: Light Scattering by Small Particles. Courier Dover, $470 \mathrm{pp}$.

Waterman, P., 1969: Scattering by dielectric obstacles. Alta Freq., 38, 348-352.

Westbrook, C. D., R. C. Ball, P. R. Field, and A. J. Heymsfield, 2004: Universality in snowflake aggregation. Geophys. Res. Lett., 31, L15104, doi:10.1029/2004GL020363.

- , - and -2006 : Radar scattering by aggregate snowflakes. Quart. J. Roy. Meteor. Soc., 132, 897-914.

R. J. Hogan, A. J. Illingworth, and E. J. O'Connor, 2007: Theory and observations of ice particle evolution in cirrus using Doppler radar: Evidence for aggregation. Geophys. Res. Lett., 34, L02824, doi:10.1029/2006GL027863.

A. J. Illingworth, E. J. O'Connor, and R. J. Hogan, 2010: Doppler lidar measurements of oriented planar ice crystals falling from supercooled and glaciated layer clouds. Quart. J. Roy. Meteor. Soc., 136, 260-276. 